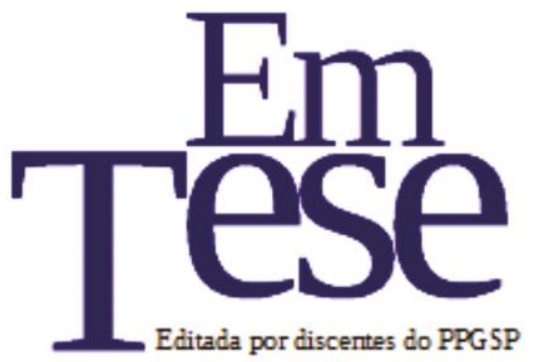

UFSC

PPG SP PROG RAMA DE

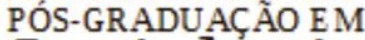

Sociologia

Política

Edita por discentes do PPGSP

v. 14 , n. 1, jan./jun., 2017

\title{
As visões de San Tiago Dantas e Roberto Mangabeira Unger acerca da Inserção Brasileira nas Relações Exteriores ${ }^{1}$
}

\author{
Carlos Henrique Aguiar Serra (UFF) ${ }^{2}$ \\ Carlos Sávio Teixeira (UFF) ${ }^{3}$
}

\begin{abstract}
Resumo: O artigo analisa a visão de San Tiago Dantas e Roberto Mangabeira Unger a respeito da ligação entre a política exterior e a política interna, investindo contra a concepção dominante hoje na literatura sobre política externa no Brasil. Em sua primeira parte, o texto se debruça sobre as ideias de San Tiago Dantas, acentuando-se o contexto em que foram produzidas noções como a de política externa independente. Na segunda parte, o artigo avança sobre a perspectiva de inserção do Brasil no mundo tal como preconizada por Roberto Mangabeira Unger, analisando-a em cotejo com suas ideias teóricas a respeito da organização das sociedades contemporâneas. Conclui, afirmando, que, para ambos, a política exterior e desenvolvimento nacional fazem parte de um mesmo processo.
\end{abstract}

Palavras-chave: San Tiago Dantas. Roberto Mangabeira Unger. Pensamento político; política externa; reforma social.

\begin{abstract}
The article analyzes the view of San Tiago Dantas and Roberto Mangabeira Unger regarding the connection between foreign policy and domestic politics, investing against the dominant conception today in the literature on foreign policy in Brazil. In its first part, the text focuses on the ideas of San Tiago Dantas, emphasizing the context in which notions such as that of independent foreign policy were produced. In the second part, the article advances the perspective of insertion of Brazil in the world as advocated by Roberto Mangabeira Unger, analyzing it in comparison with its theoretical ideas regarding the organization of contemporary societies. It concludes by stating that, for both, foreign policy and national development are part of the same process.
\end{abstract}

Key words: San Tiago Dantas; Roberto Mangabeira Unger: political thought; foreign policy; social reform.

\footnotetext{
${ }^{1}$ Este artigo é uma versão modificada de texto apresentado no $9^{\circ}$. Encontro da Associação Brasileira de Ciência Política (ABCP), ocorrido em Brasília-DF, em agosto de 2014.

${ }^{2}$ Doutor em História pela UFF. Professor Associado de Ciência Política do Departamento e Programa de PósGraduação em Ciência Política da UFF. Coordenador do Programa de Pós-Graduação em Ciência Política da UFF. Trabalha nas áreas relativas ao pensamento social e político no Brasil e também, sobre violência, punição e criminalidade no Brasil.

${ }^{3}$ Doutor em Ciência Política pela USP. Atualmente é Professor Adjunto do Departamento de Ciência Política da UFF, no qual exerce o cargo de Chefe de Departamento. Desenvolve pesquisas sobre o pensamento social Brasileiro e sua relação com os projetos de desenvolvimento do país e sobre o debate acerca das alternativas institucionais contemporâneas. E-mail: carlos.savio.teixeira@gmail.com
} 


\section{Apresentação}

A preocupação com o tema da inserção do Brasil no mundo é antiga. Faz parte, inclusive, da própria busca do país em construir a sua identidade nacional. San Tiago Dantas e Roberto Mangabeira Unger integram o elenco de autores que formularam ideias a respeito daquele processo. Para ambos, política externa de um país como o Brasil deve estabelecer plena sintonia com política interna. Partindo deste princípio, construíram visões acerca de como a realidade nacional deveria informar o projeto externo brasileiro em cada um dos contextos de suas reflexões.

Trata-se de dois autores que se inscrevem no âmbito do pensamento político brasileiro contemporâneo e suas ideias são relevantes para uma melhor compreensão dos cenários políticos no Brasil, do fim da década de 1950 até a conjuntura atual. Interessante observar também que as ideias de Dantas e Unger estabelecem estreita interface, por exemplo, entre os campos da Filosofia Política, Teoria Social e Direito.

$\mathrm{Na}$ análise a respeito do pensamento político de San Tiago Dantas, particularmente, considerando o período que cobre o fim da década de 1950 e vai até setembro de 1964, quando o autor vem a falecer, encontramos algumas questões que ainda hoje são de extrema validade e dizem respeito ás concepções do autor acerca da política externa e do projeto político de reforma social.

No que concerne à política externa, San Tiago, por exemplo, que postulava de forma contundente a política externa independente, defendia intransigentemente os princípios da nãointervenção, solidariedade entre os povos, anticolonialíssimo, autodeterminação dos povos e coexistência pacífica.

De forma análoga à elaboração e defesa da política externa, o projeto político de reforma social do autor, que foi explicitado em 1963, visava alguns pontos ainda hoje bastante significativos tais como: a) reforma incorporada às aspirações do povo; b) reforma que atinja de frente o problema da segurança econômica de cada indivíduo; c) reforma que terá de produzir uma distribuição da renda social.

Em Roberto Mangabeira Unger, autor que se encontra radicado nos EUA, na Universidade de Harvard, desde o início da década de 1970:

O Brasil representa o mundo em que as questões fundamentais apareceram em sua forma mais rica, não apenas como ideias ou doutrinas, mas como encruzilhadas coletivas e individuais. A parte mais importante de seu pensamento, a dedicada à política, está sempre inspirada simultaneamente por uma construção teórica a respeito da sociedade e da história universais e por um confronto com o mundo brasileiro. Em seu pensamento não há uma escolha entre o universal e o local. O local é a manifestação do universal, no sentido de que existe uma cadeia de analogias que ligam o Brasil ao restante do mundo. Tanto a sua interpretação dos constrangimentos brasileiros quanto sua proposta de reorganização institucional do Brasil são o reflexo dessa dialética (TEIXEIRA, 2013). 
A obra de Unger dedicada ao Brasil apresenta duas perspectivas. De um lado, uma preocupação substantiva e, de outro, uma ambição metodológica. A primeira oferece uma visão abrangente acerca do país, ancorada em ideias formuladas por sua teoria social. A segunda procura construir uma maneira de pensar e propor programaticamente. Os seus escritos evidenciam tanto o amadurecimento da preocupação substantiva, como a redefinição da prática metodológica. Cada vez menos os textos contendo as análises e as propostas programáticas brasileiras tomam a forma de um receituário fechado. Ao contrário, elas passam a indicar a demarcação de uma direção, apresentada em inúmeros exemplos de possíveis iniciativas ${ }^{4}$.

Desta forma, pode-se acrescentar ainda que as propostas de reorganização institucional do país defendidas por Unger também se afastam de muitos dos principais projetos de modernização formulados pelo pensamento político brasileiro. Um dos temas principais de nosso pensamento político foi a construção do projeto de um Estado Nacional. Na maioria das vezes a formulação desse projeto expressou uma visão política e econômica quase sempre marcadas pelo autoritarismo e pelo dirigismo tecnocrático. Essas tendências foram inspiradas pelo positivismo reinante no século XIX e deixaram o seu legado no século XX. A ideia básica do projeto supõe uma vanguarda esclarecida que constrói o Estado forte e usa esse Estado para definir, de cima para baixo, uma trajetória independente para o país.

As ideias de San Tiago Dantas e Roberto Mangabeira Unger, apesar dos contextos distintos e ambições teóricas diferentes, possuem algumas similaridades, portanto, aproximações, no que concerne à concepção de cada autor a respeito da dialética entre política externa e projeto político de organização social interno da sociedade brasileira.

O objetivo central deste artigo consiste na reflexão acerca da proposta de política externa elaborada por cada autor e que estabelece uma sintonia entre ambos.

Para fins de uma melhor compreensão, este artigo divide-se em três partes que se interligam: na primeira, há uma discussão a respeito da proposta de política externa independente, sob a chancela de San Tiago Dantas, e seus desdobramentos para o projeto político de reforma social. Na segunda, há uma análise sobre as proposições de Roberto Mangabeira Unger. Na última parte, nas considerações finais do trabalho, busca-se explorar melhor as similitudes existentes entre os autores.

\footnotetext{
${ }^{4}$ A produção bibliográfica de Unger sobre o Brasil compõe-se de inúmeros artigos e entrevistas apresentados na imprensa e de quatro livros publicados que procuram dar conta, em momentos específicos da vida nacional, de sua compreensão dos limites e das oportunidades do país. Os dois livros sobre o Brasil que revelam uma análise substantiva da realidade do país são os seguintes: A Alternativa Transformadora: Como Democratizar o Brasil, de 1990 e A Segunda Via: Presente e Futuro do Brasil, publicado em 2001. Em 1998, Unger iniciou contribuição regular ao jornal Folha de São Paulo onde manteve uma coluna semanal até a sua entrada no governo Lula na condição de ministro em junho 2007.
} 


\section{A política externa independente e o projeto de reforma social em San Tiago Dantas}

Sustentamos que as ideias de San Tiago Dantas, tanto no que concerne à Política Externa Independente (PEI), como também, em relação ao projeto de reforma social, que guardam estreita ligação, são ainda pertinentes.

Assim sendo, revisitar o pensamento político de San Tiago Dantas (SERRA, 1991) acerca da Política Externa Independente no atual cenário, numa conjuntura ainda marcada por tensões existentes entre distintas Nações-Estados e seus respectivos projetos de construção e fortalecimento de hegemonias, consiste na possibilidade interpretativa de se repensar as ideias deste autor, e, portanto, dar relevo à defesa enfática deste autor sobre a importância para o Brasil de consagrar uma política externa independente.

Dantas costumava destacar que "os povos, primeiro, precisam desenvolver-se, para depois, obter a independência. Sabemos que é exatamente o oposto disto o que a História nos ensina e o bom senso nos aconselha. Só os povos que se tornam independentes conseguem desenvolver-se". (DANTAS, 1983)

A busca pela independência e, portanto, autonomia do Brasil, era, para San Tiago, algo primordial.

Numa conjuntura política muito conturbada e marcada por radicalizações políticas nos dois campos ideológicos, e ainda considerando os efeitos produzidos pela Revolução Cubana, em 1959, as posições defendidas por San Tiago Dantas, a partir daquele momento histórico, por exemplo, merecem destaque.

Desta forma, por exemplo, cabe registro o papel que Dantas exerceu como Conselheiro da Delegação Brasileira à V Reunião de Consulta dos Chanceleres Americanos, em Santiago do Chile, realizada no período de 12 de agosto de 1959 a 18 de agosto de 1959.

Nesta V Reunião, San Tiago Dantas estabelece os principais alicerces de sua PEI, defendendo-a enfaticamente na conturbada conjuntura político-ideológica de 1961-1962.

Identificamos que os princípios do não intervencionismo e anticolonialismo se configuram como pontos essenciais, no entendimento do autor, para o fortalecimento da democracia representativa e dos regimes democráticos do Ocidente.

Entretanto, há um ponto que se sobressai aos demais, presente nas ideias de San Tiago, tanto na sua proposta por uma política externa independente, como também no seu projeto político de reforma social: a preservação da paz.

Assim, ao defender o fortalecimento da democracia representativa no ocidente, o autor busca evitar um conflito mundial entre os países.

Em linhas gerais, os alicerces da Política Externa Independente, postulada por San Tiago Dantas nos anos de 1961-1962, estabelecidos na Declaração de Santiago do Chile, em 1959, são 
principalmente estes: 1) princípio de não-intervenção; 2) anticolonialismo; 3) solidariedade entre os países; 4) luta pela preservação da paz.

Nos anos 1961-1962, o governo brasileiro começa a dar passos decisivos na construção da Política Externa Independente e tais passos, conforme sustentamos neste trabalho, possuem em San Tiago Dantas o seu principal articulador e defensor.

Percebe-se na sua defesa pela PEI, no que tange principalmente à autonomia do país, uma sintonia intensa com a política interna.

Assim sendo, sustentamos que a defesa por uma política externa independente, o país assumindo seu protagonismo, se coaduna também na elaboração do projeto político de reforma social.

Cabe destacar ainda que primeiro com Afonso Arinos, e depois com San Tiago Dantas foram "cortadas as amarras" que prendiam o Brasil a sua própria insegurança. Desta forma, ainda segundo San Tiago, o país apesar da intensa oposição, "reatou relações diplomáticas com a União Soviética e passou a adotar em relação a Cuba uma atitude de firme e digno respeito à autodeterminação dos povos". (DANTAS, 1962)

É na sessão da Câmara dos Deputados, em 24 de agosto de 1961, quando renuncia ao mandato de Deputado Federal, pelo PTB/MG, para aceitar a designação para Delegado Permanente do Brasil na ONU, que San Tiago Dantas formula a Política Externa Independente.

San Tiago Dantas sublinha que em cada atitude, sempre esteve presente uma questão fundamental que diz respeito à "consideração exclusiva do interesse do Brasil, visto como um país que aspira (I) ao desenvolvimento e à emancipação econômica e (II) à conciliação histórica entre o regime democrático representativo e uma reforma social capaz de suprimir a opressão da classe trabalhadora pela classe proprietária.” (DANTAS, 1962)

Nesta passagem, pode-se observar de forma bem clara a sintonia existente entre a política externa independente e o projeto político de reforma social.

O recurso usado por San Tiago à conciliação deve ser compreendido no sentido preciso de que o autor, fiel ao princípio "the rule of Law", almeja o equilíbrio nas ações políticas, tanto no plano externo como no plano interno.

$\mathrm{O}$ autor, na verdade, movimentava-se exclusivamente, na tentativa de evitar a radicalização do processo político no país, na defesa pela preservação da paz, embutida no projeto político de conciliação, que repudiava os conflitos tanto internamente como externamente.

Identificamos, em linhas gerais, conforme visão de San Tiago Dantas, que a proposta da PEI contemplava os seguintes aspectos: 1) relações diplomáticas e intercâmbio comercial e cultural com todos os povos. Reformulação e aprimoramento do pan-americanismo, visando eliminar as causas do pauperismo e do subdesenvolvimento continentais; 2) repúdio à guerra, às 
competições armamentistas, no emprego de armas de extermínio indiscriminado e às experiências atômicas e termonucleares para fins bélicos; 3) luta contra o imperialismo e o colonialismo e condenação a todas as formas de agressão, intervenção e pressão econômica; 4) livre determinação dos povos na escolha de seus dirigentes e de suas formas de governo; 5) arbitragem nos litígios e conflitos internacionais.

Esta proposta, na nossa interpretação, ainda é muito pertinente e atual, não obstante os mais de 50 anos que a separam do cenário político contemporâneo, pois os princípios, por exemplo, de repúdio ao imperialismo e colonialismo, defesa pela autodeterminação dos povos, coexistência pacífica e preservação da paz, são relevantes neste cenário.

O que está intrínseco nos princípios de não-intervenção, anticolonialismo, e no próprio postulado da política externa, é o significado da independência para San Tiago Dantas. Para o autor, a

Independência é, acima de tudo, aquela posição que não se curva aos interesses de um bloco nem do outro, que não deseja ver a sua conduta internacional predeterminada por uma aliança ou já decidida por determinadas afinidades políticas consideradas, de modo sistemático, como irremediáveis (DANTAS, 1962).

San Tiago almeja para o país um caminho próprio que o conduza inexoravelmente ao desenvolvimento e emancipação econômica. Assim, a independência representa para o autor estar em plena sintonia com os interesses exclusivos do Brasil e desta forma, conduzir o país ao desenvolvimento econômico, já devidamente assegurada a independência.

Desta forma, ser independente é poder dialogar, por um lado, com o bloco do Ocidente, e, por outro, com o bloco do Oriente. Significa, portanto, uma política externa não subserviente e não submissa em relação aos blocos do Ocidente e Oriente. Eis o caráter racionalista e pragmático de sua política externa.

O autor ao postular o reatamento das relações com a União Soviética busca preservar a paz e viabilizar a solidariedade, equilíbrio e consenso entre os países. Não obstante toda a intensa oposição feita pelos segmentos mais conservadores e reacionários do país aos princípios expressos na PEI, San Tiago manteve-se firme na defesa de cada aspecto presente na PEI.

Há dois aspectos que se imbricam na defesa do autor pelo reatamento das relações diplomáticas e comerciais com a União Soviética: a preservação da paz e a crítica enfática à política do isolacionismo.

Cumpre ainda ressaltar que San Tiago Dantas afirma reiteradas vezes que estava reatando relações diplomáticas e comerciais com a União Soviética e não com o comunismo; isto é, embora não sendo comunista, tal fato não era obstáculo para o reatamento com a URSS. Na verdade, San Tiago sempre opôs o regime professado no ocidente, a democracia representativa, ao do oriente, o socialismo, este visto pelo autor como sendo um regime autoritário.

Observamos que San Tiago Dantas é incansável na sua defesa pela paz, pois sustenta que 
se deseja a paz, em última instância,

Temos de ser os advogados da coexistência e não podemos admitir que se parta do princípio de que o regime democrático é dotado de tal fragilidade, que se for posto em contato e em confrontação com os regimes socialistas, o seu destino estará selado. (DANTAS, 1962).

Identificamos no pensamento de San Tiago Dantas, de corte liberal, e que em determinados momentos históricos, como na elaboração da Política Externa Independente, possui traços de um "liberalismo radical", uma nítida distinção deste pensamento com o autoritário-reacionário, de alguns setores da sociedade brasileira, que não toleravam de forma alguma, por exemplo, o reatamento com a URSS.

Na visão de San Tiago, o caminho que o Brasil tinha que seguir para efetivar o "projeto nacional" contemplava três aspectos fundamentais: 1) mercado Latino-Americano; 2) mercado tradicional dos Estados Unidos da América do Norte; 3) os países que integravam o bloco socialista. (SERRA, 1991)

O autor é muito explícito na visão para a independência do país: a política externa e a política interna, leia-se o projeto de reforma social, devem estar intimamente imbricados.

A radicalização do processo político, nos anos 1961-1964, produziu múltiplos efeitos no pensamento político de San Tiago Dantas e esta consideração vale tanto para a proposta da PEI, formulada pelo autor, como também, no que diz respeito ao projeto de reforma social.

$\mathrm{O}$ pensamento político do autor trazia consigo um veio pragmático-racionalista $\mathrm{e}$ nacional-independente. Era também profundamente avesso a toda e qualquer radicalização política, pois concebia que os "extremismos" eram profundamente prejudiciais à "democracia" e, também, à "reforma social”. (SERRA, 1991)

No auge da radicalização política, anos 1963-9164, San Tiago cunhou as expressões "esquerda positiva" e "esquerda negativa". Esta, segundo o autor, apostava na radicalização do processo político, no aguçamento das lutas de classes, e, então, seus principais representantes eram Leonel Brizola, Miguel Arraes e Francisco Julião. Já, na visão do autor, a "esquerda positiva" era a esquerda responsável, que buscava o equilíbrio, a conciliação, que repudiava, portanto, a radicalização e que apostava na relação intrínseca entre democracia e reforma social. (SERRA, 1991)

Na sua proposta de reforma social, dois aspectos são imprescindíveis (SERRA, 1991): a) a certeza de que a sobrevivência da democracia e da liberdade, no mundo moderno, depende de nossa capacidade de estendermos a todo o povo, e não de forma potencial, mas efetiva, os benefícios, hoje reservados a uma classe dominante, dessa liberdade e da própria civilização; b) a certeza de que a continuidade da civilização, com o seu resultado final que é a reconciliação dos homens, depende da nossa capacidade de preservar a paz, substituindo a competição militar entre 
os povos por técnicas cada vez mais estáveis de cooperação e de convivência, e caminhando para uma integração econômica que nivele as oportunidades, com a rápida eliminação dos resíduos do imperialismo e das rivalidades nacionais.

Na tentativa de preservar o vínculo entre democracia e reforma social, o projeto político de reforma social do autor baseava-se em três pontos (SERRA, 1991): 1) terá de ser uma reforma incorporada às aspirações do povo, que suba das próprias bases sociais, debatida e filtrada nas organizações de classe, e não uma reforma outorgada pela classe dominante, expressiva apenas de uma concessão sem conciliação; 2) terá de ser uma reforma que fira de frente o problema vital da segurança econômica do indivíduo na sociedade, pois na sociedade burguesa, em cujas formas já decompostas ainda vivemos, a segurança econômica é o privilégio do proprietário, do chamado homem-independente, enquanto a forma universal de participação do indivíduo na sociedade é o trabalho, e o status que a todos corresponde é o de trabalhador; 3 ) terá de produzir, a curto prazo e sem violência, com respeito dos direitos subjetivos, uma redistribuição da renda social, de modo que esta, através do salário, dos serviços coletivos e dos investimentos no setor público e privado, atinja a sociedade no seu todo, eleve o padrão de vida e crie o número crescente de ocupações e atividades requeridas pelo aumento e pela ativação da população.

Nesse sentido, para se compreender melhor a sintonia existente, no pensamento do autor, entre política externa e projeto de reforma social, é mister explicitar a sua defesa enfática contra os “extremismos”, mas sim pela "radicalização de ideias" (SERRA, 1991).

San Tiago, então, enfatiza que já denunciou "uma vez o negativismo de certas atitudes ideológicas, de sentido pseudo-revolucionário, que se colocam contra o processo dialético e retardam, em vez de acelerar, a superação de contradições” (DANTAS, 1963).

$\mathrm{Na}$ nossa concepção, este processo dialético configura-se na essência da sintonia existente entre a proposta da política externa independente e o projeto político de reforma social, pois, conforme o próprio San Tiago salientava, “é do ajustamento perfeito entre elites capazes de se modernizarem e o povo, que nos testemunha todos os dias sua vitalidade, que sinceramente espero ver surgir, por eletrólise, essa realidade que pressentimos: o futuro do Brasil". (SERRA, 1991)

\section{A presença do Brasil no Mundo sob a visão de Roberto Mangabeira Unger}

Separados por uma geração, San Tiago Dantas e Roberto Mangabeira Unger possuem características políticas e intelectuais que os aproximam e os distanciam. Talvez, o traço mais convergente entre as suas trajetórias seja a atuação pública junto á figuras do Trabalhismo Histórico Brasileiro, sendo Dantas ministro do governo João Goulart e Unger um conselheiro muito próximo de Leonel Brizola. Entre as diferenças, talvez a mais significativa seja o fato de 
que Dantas foi um intelectual de alcance nacional enquanto Unger é um teórico social com uma obra de abrangência internacional ${ }^{5}$.

O esforço de construção explicativa de Unger acerca do Brasil e suas análises a respeito da dialética entre a realidade nacional e o contexto internacional foram formulados a partir de uma extensa teoria social e política produzida ao longo das últimas quatro décadas. No que interessa mais de perto a este texto, a questão que o ocupou foi a formação de um pensamento verdadeiramente institucional capaz de estimular a prática disciplinada da imaginação institucional, em sua avaliação, a grande lacuna do pensamento social contemporâneo ${ }^{6}$.

Para Unger o traço mais característico das sociedades contemporâneas é a indefinição institucional de suas dimensões econômica e política, circunstância esta pouco explorada por áreas como a economia política. Em sua perspectiva, isso impede o aproveitamento analítico de uma das mudanças mais significativas no mundo atual que é a alteração do enfoque do conflito ideológico que deixou de ser a velha oposição entre estatismo e privatismo e passou a ser o conflito emergente entre as formas institucionais alternativas do pluralismo político, econômico e social (UNGER, 1999).

Na questão da relação entre as realidades nacionais e a ordem internacional, colocado no pensamento brasileiro pelas categorias centro e periferia, a sua idéia básica é que a história não é uma máquina que reproduza de forma permanente relações de centro e periferia: os países que agora são predominantes, sobretudo os Estados Unidos, se tornaram predominantes porque combinaram uma fórmula institucional exitosa com um projeto ideológico sedutor para a maior parte da humanidade. Não há nenhuma justificativa intelectual ou científica que autorize a idéia de que os poderes econômicos e militares propiciados por essa fórmula e sua sedução ideológica não possam ser desgarrados da sua base e reinventados com conteúdo e forma distintos em outro contexto. O caso da China hoje pode ser tomado como um exemplo empírico do princípio ${ }^{7}$.

Em suas formulações sobre a questão, Unger tem procurado operar analiticamente em dois planos simultâneos: "rebelião nacional e organização internacional". De um lado, propõe formas alternativas de globalização - a reorientação do regime internacional do comércio, a reorganização das instituições multilaterais do sistema Bretton Woods e um conjunto de entendimentos entre as potências médias (China, Rússia, Índia e Brasil) que permitiriam, pouco a pouco, transformar a natureza da hegemonia americana. Tudo isso para criar uma forma de globalização mais propicia ao "pluralismo". De outro lado, sustenta que a energia para lutar por essa reconstrução do regime global tem de vir da tentativa de reorientar os projetos nacionais:

\footnotetext{
${ }^{5}$ Para se obter uma visão panorâmica sobre a obra de Unger ver o livro de Lovin e Perry (1987). Há também um ensaio de Perry Anderson intitulado "A Política do Engrandecimento", onde ele apresenta e discute os principais marcadores teóricos do pensamento de Unger. Ver Anderson (2002, p. 173-194).

${ }^{6}$ Ver, a respeito da visão de Unger sobre o pensamento social contemporâneo, Unger (1987).

${ }^{7}$ Para uma análise de fundo histórico do argumento teórico produzido pelo pensador brasileiro, ver Unger (1987).
} 
somente quando se tenta desenvolver um projeto nacional alternativo ao limitado pela forma atual de globalização, torna-se possível levar adiante essa idéia de mudar as regras da globalização ${ }^{8}$.

O problema para um país como o Brasil é justamente o fato de não se ter a consciência teórica clara desta circunstância. No momento em que o Brasil se situa com maior destaque no cenário mundial, duas anomalias ganham evidência ao se observar a política externa brasileira: 1) o fato de a nossa política exterior não ser questão central nem para o Estado nem para a sociedade. Ao contrário de todas as grandes democracias contemporâneas a política externa brasileira não é tema debatido na política nacional; 2) a consequência desta circunstância nociva é que a política externa brasileira, especialmente a partir da ditadura militar, sofreu um desvio incompatível com o papel central da política exterior numa ordem democrática. Tendo em vista o cunho periférico da política exterior dentro da política nacional durante a ditadura militar, permitiu-se que os diplomatas formulassem livremente a política exterior ${ }^{9}$.

Essas duas circunstâncias revelam muito mais que uma simples falha secundária. Para um país emergente como o Brasil, a maneira de se inserir na divisão internacional do trabalho e ganhar acesso aos grandes mercados mundiais representa preocupação incontornável. Política exterior, porém, integra a política estratégica de um país, e não deve, portanto, ser tratada apenas como ramo do comércio. Todas as grandes potências da história moderna entenderam que os objetivos comerciais, embora importantes, são acessórios aos propósitos geopolíticos ou estratégicos. Não se trata de purismo doutrinário. Trata-se de realidade prática: o êxito das próprias reivindicações comerciais costuma depender do respaldo de poder e de política com que o país conta. A premissa é que poder vale mais do que dinheiro.

Colide com essa visão as duas preocupações mais fortes da diplomacia brasileira nas últimas décadas. A obsessão de nossos diplomatas tem sido a Rodada de Doha e o assento no Conselho de Segurança da ONU. Como referido antes, eles exemplificam os dois temas dominantes na mentalidade que, em nossa história recente, influenciaram a formação da política exterior: negociação comercial e protagonismo internacional ${ }^{10}$. Para Unger, à medida que a

\footnotetext{
${ }^{8}$ Unger (2010). Nesta obra, que integra o seu projeto intelectual de repensar e propor a reorganização das instituições do mundo contemporâneo, Unger mobiliza três grandes ideias: 1) a revisão da teoria econômica; 2) a reconstrução da economia de mercado; 3) reorientação da globalização.

${ }^{9}$ Neste ponto não se trata apenas do fato de que nas principais democracias do mundo a política exterior é forjada no debate nacional e definida pelo governo eleito, por uma questão de legitimidade, mas também por causa da substância da política exterior. Para Unger, a geração de diplomatas que hoje se encontra na primeira escala da carreira formou-se no regime militar. Privilegiou, sob aquele regime, os dois temas mais aceitáveis aos militares: negociações comerciais e projeção de prestígio (manifesta, sobretudo, em maior representação dentro das organizações internacionais). Aquilo que fora tática de sobrevivência virou, com o passar do tempo, convicção.

${ }^{10}$ Em artigo sobre o tema, Unger afirma sem rodeios que "O Brasil não tem política exterior. Em vez dela, tem uma prática minúscula e malograda de negociações comerciais. (...) Os defensores da redução da política exterior a negociações comerciais afundaram num pragmatismo antipragmático. Prometeram resultados e entregaram frustrações. A única iniciativa forte da diplomacia brasileira, o Mercosul, agoniza e só ressurgirá se for reconstruída radicalmente. A razão básica pela qual não temos política externa é que não temos projeto interno, a não ser um
} 
política exterior ganhar a centralidade que merece em nosso debate nacional, e os diplomatas deixarem de tentar formulá-la em vez de executá-la, estas preocupações, embora legítimas, ficarão reduzidas a dimensões mais modestas e apropriadas. Figurarão, entre muitas outras iniciativas, dentro de uma política de Estado de aspirações mais amplas ${ }^{11}$.

Até mesmo uma visão mais estreita a respeito da política exterior deve reconhecer que a perseguição de motivos estritamente econômicos depende, também, do regime e das regras do comércio internacional. A implicação prática deste raciocínio é que o Brasil precisa ter estratégia de inserção no mundo que não se reduza às negociações comerciais específicas, à projeção de prestígio ou ao alcance de maior presença nas organizações internacionais existentes - a começar pelas organizações do sistema Nações Unidos e do sistema Bretton Woods. Isso significa, entre outras coisas, ter proposta e plano de ação para influir na reconstrução da ordem mundial, inclusive do regime mundial de comércio ${ }^{12}$.

Em seu livro A Reinvenção do Livre Comércio, Unger sustenta ser altamente nociva a evolução do regime internacional do comércio, sob a OMC, que caminha no sentido de um maximalismo institucional: a tendência de impor aos países comerciantes em nome do livre comércio não apenas o compromisso com a economia de mercado, mas o compromisso com um tipo particular de economia de mercado. É um exemplo disso a proibição, sob o rótulo de subsídios, de todas as formas de coordenação estratégica entre governos e empresas que os países hoje ricos usaram, com a única possível exceção da Grã-Bretanha, em suas estratégias de enriquecimento. O interesse de um país como o Brasil é substituir o maximalismo institucional por um minimalismo institucional em matéria de regime de comércio. O máximo de abertura econômica com o mínimo de regras restritivas. Esse é um exemplo do interesse maior em construir uma ordem econômica internacional mais propícia ao pluralismo de poder e de visão do que ela ostenta hoje.

Para Unger, existem no cenário atual dois tipos de oportunidades para mudar um quadro como o brasileiro: as de ordem política e as de natureza intelectual. De um lado, a situação dos grandes países continentais marginalizados, como a China, a Rússia, a Índia e o Brasil, países que se encontram em situação relativamente privilegiada para que ocorra o desenvolvimento de

projeto que resultou no enfraquecimento progressivo da nossa afirmação nacional e que inibiu o dinamismo extraordinário da nossa economia." (UNGER, 2002, p. 3).

${ }^{11} \mathrm{O}$ ponto mais espinhoso nesta questão é assegurar que essa nova perspectiva sobre política externa que necessariamente gerará uma nova divisão de responsabilidades entre a política e a diplomacia se consuma de maneira a fortalecer a concepção e a prática da política exterior como política de Estado, e não apenas política de governo. O que não se deve e precisa tolerar é que o preço da construção da política exterior como política de Estado seja sua delegação a uma corporação profissional: a dos diplomatas. Unger é categórico: "É exatamente o mesmo problema que enfrentamos com respeito à política de defesa. É inaceitável, quer em relação à política exterior, quer com respeito à política de defesa, que a afirmação do cunho de política de Estado signifique a usurpação, pelos diplomatas ou pelos militares, da prerrogativa de defini-las. Ou que a superação de tal desvirtuamento resulte na redução da política exterior a joguete de sectarismo partidário.” (UNGER, 2009, p. 5).

${ }^{12}$ Para uma discussão teórica das teses de Unger sobre a economia internacional no atual período de globalização ver Unger (2010). 
alternativas institucionais ao padrão dominante no Ocidente. De outro lado, a oportunidade intelectual está no fato de que em teorias como o marxismo e as ciências sociais tal como praticada na academia dos EUA e em seus satélites periféricos o entendimento da história e da sociedade formou-se a serviço da ideia de destino, e não a serviço da ideia de construção e reconstrução. Por isso, a tarefa mais urgente do pensamento social é forjar os instrumentos intelectuais com que imaginar estas alternativas a que o novo conflito de ideias se abre ${ }^{13}$.

A concepção analítica central mobilizada para o aproveitamento dessas oportunidades é a ideia de indefinição institucional da economia de mercado e da democracia representativa. Ou seja, a economia de mercado não tem uma forma institucional singular: pode assumir formas institucionais muito variadas, com consequências fortes, não só para a distribuição da riqueza e do poder, mas para a organização de toda a sociedade. Esta ideia de indefinição institucional da economia de mercado desdobra-se em várias preocupações mais específicas ao longo do pensamento de Unger. Enumeram-se três cenários ou exemplos de situação onde se apresenta a indefinição institucional da economia de mercado atualmente.

Primeiro, o relacionamento entre os setores mais avançados e mais atrasados da economia, isto é, a vanguarda e a retaguarda produtivas. A economia mundial está organizada como uma confederação internacional de vanguardas produtivas. Definidas estas vanguardas, menos por capital e tecnologia do que por um método de inovação permanente, observa-se que estas vanguardas produtivas estão em cada país - rico ou pobre - separadas de suas respectivas retaguardas. Os dois mecanismos existentes no mundo para moderar as consequiências desigualizadoras dessa divisão entre vanguarda e retaguarda, que são as políticas sociais compensatórias e a difusão politicamente sustentada da pequena propriedade, padecem do mesmo defeito: não guardar uma relação íntima com a lógica central da inovação e do crescimento. Portanto, se apresentaram ao longo do tempo como um ônus sobre o crescimento e não uma parte dele. A questão, então, é a seguinte: a forma institucional da organização da economia de mercado tanto pode aprofundar essa divisão supra referida como pode iniciar um processo de sua superação. Dessa forma, o problema é saber se estamos condenados a apenas

\footnotetext{
${ }^{13}$ O livro Democracia Realizada: A Alternativa Progressista, de Unger, é um esforço de ligar estes dois aspectos da situação contemporânea, mostrando como relacionar a reconstrução do aparato explicativo do pensamento social contemporâneo crítico à formulação de alternativas institucionais. No caso das alternativas no campo econômico, "o cerne intuitivo da proposta de Unger de reconstrução econômica está na tentativa de substituir a demanda de garantia de emprego pelo aumento dos recursos e capacidades de cada trabalhador-cidadão, e na substituição do reconhecimento, valorizado pela social-democracia, dos grupos de interessados (stakeholders) pela diversificação e descentralização radicais das formas de acesso às oportunidades produtivas. A primeira proposta dessa plataforma conduz à generalização da herança social por meio de contas de subvenção social a que todos terão acesso; a segunda, à desagregação da propriedade privada tradicional, recombinando e realocando seus elementos constitutivos. As duas propostas, por sua vez, devem ser sustentadas por instituições e práticas que incentivem a aceleração da política democrática e a auto-organização independente da sociedade civil. Os instrumentos tradicionais do constitucionalismo liberal são inadequados para a primeira, da mesma forma que o repertório familiar do direito contratual e societário são insuficientes para a segunda”. (CUI, 2001, p. 19).
} 
moderar as consequências sociais dessa divisão ou se, ao contrário, temos a condição de enfrentá-la e superá-la (UNGER, 1999).

Em segundo lugar, o relacionamento entre finanças e produção. A forma institucional de economia de mercado que triunfou nos países do chamado primeiro mundo, deixa tênue a relação entre poupança e produção. "A evolução da teoria econômica dificulta até formular essa questão na medida em que tende a transformar numa equivalência semântica investimento e poupança”. Para Unger, a questão da relação entre finanças ou poupança de um lado e, produção ou investimento produtivo de outro, não é uma questão analítica e sim institucional: depende de saber se de fato existem alternativas institucionais que possam relacionar mais intimamente o dinheiro com a economia real (UNGER, 2009).

O terceiro aspecto da oportunidade é a participação do salário na renda nacional. Segundo Unger, as grandes variações que existem entre países em níveis semelhantes de riqueza e desenvolvimento na participação dos salários na renda nacional não podem ser explicadas exclusivamente por fatores econômicos ou demográficos. Têm de ser explicados também por circunstâncias políticas e institucionais. Portanto, “o dogma quase universalmente aceito de que não pode haver crescimento dessa participação dos salários na renda que ultrapasse ganhos da produtividade é falso" (UNGER, 1999, p. 136). Esta ideia de que o status do salário do trabalhador depende do contexto ou da forma institucional da economia de mercado tem uma contrapartida em outra tese sobre o caminho para a construção de uma economia mundial livre.

O modelo neoliberal adotou como estratégia o livre comércio e o livre fluxo de capitais acompanhado pelo aprisionamento do trabalho em Estados-nação relativamente homogêneo como a comunidade europeia. Unger defende um caminho alternativo em que o capital e o trabalho ganhem juntos, porém, em pequenos passos gradativos, essa liberdade para atravessar fronteiras. Pois a ideia de indefinição da economia de mercado se opõe a tese da convergência, segundo a qual todas as economias do mundo evoluem para os mesmos conjuntos de práticas e instituições ${ }^{14}$.

Nessa perspectiva, as diferenças institucionais entre as formas de capitalismo, como as diferenças de organização societária da economia de mercado alemã ou japonesa em

\footnotetext{
${ }^{14}$ As premissas sobre a realidade "indisputada" acerca da realidade da ordem internacional que justificam a adoção da tese da convergência se assentam nas seguintes ideias: 1) a emergência de um mercado global nas últimas décadas; 2) esse processo resultou da aplicação das inovações tecnológicas mais recentes - a combinação de telecomunicações com informática - à operação dos mercados internacionais de capitais, conferindo enorme mobilidade às aplicações financeiras que promovem os investimentos; 3) dessa forma tornaram-se inócuas as tentativas de controle e/ou intervenção por parte dos estados nacionais; 4) diante disto, os estados viram-se obrigados a liberalizar e desregular as suas economias para dar conta da nova mobilidade e velocidade alcançada pelo capital; 5) com isso os estados - de forma generalizada - perderam capacidade de gestão macroeconômica abrindo caminho para a convergência econômica mundial das mesmas práticas e instituições. Embora muitos abracem esta tese, a adesão aos itens do pacote varia de acordo com cada autor. Uma versão ambiciosa intelectualmente e abertamente ideológica dessa tese foi formulada por Francis Fukuyama (1992).
} 
comparação com a norte-americana, seriam limitadas e efêmeras. Para Unger, uma comparação convincente entre as economias desses países deve inverter o argumento: essas variações institucionais existentes, ainda que sejam transitórias, representam uma parcela ou seguimento de um universo muito mais amplo de possibilidades institucionais. Essa concepção analítica informa no seu pensamento o argumento programático: a defesa de um experimentalismo institucional tanto produtivo como político ${ }^{15}$.

Em contrapartida às oportunidades intelectuais existem hoje três tipos de oportunidade políticas ou práticas concretas que servem de incitamento para o projeto preconizado por Unger. Primeiro, a convicção das limitações do compromisso social-democrata do segundo pósguerra que, basicamente, abandonou a tentativa de reinventar a forma institucional do mercado e da democracia, substituindo esse esforço de reinvenção institucional por um compromisso com a democratização das oportunidades de consumo e pelo manejo contra cíclicos das economias. Esses compromissos sociais democratas, de fato, têm limites cada vez mais patentes ${ }^{16}$. O argumento de Unger é que esse compromisso keynesiano baseado numa série de barganhas entre grandes interesses organizados - parecendo até uma espécie de novo "antigo regime" - restringe a força de inovação econômica e tecnológica e, ao mesmo tempo, supõe uma série de divisões existentes entre grupos organizados ou trabalhadores que desfrutam dos melhores empregos e grupos desorganizados ou trabalhadores excluídos ${ }^{17}$.

A segunda oportunidade prática para o desenvolvimento desse projeto é a ideia de que já está em curso em todo o mundo - sobretudo nas economias ricas - uma mudança do padrão produtivo. Essa mudança é às vezes descrita como um pós- fordismo, ou como uma economia flexível e inovadora. Nessa descrição, seria uma forma de produção que modera o contraste

\footnotetext{
${ }^{15} \mathrm{O}$ resultado esperado dessa ideia programática é que a descentralização política e produtiva leve a uma segunda etapa em que a forma de economia verdadeiramente democratizada de mercado abrigaria regimes alternativos de propriedade privada e social, coexistindo experimentalmente na mesma economia. Ao invés de apegar-se a uma forma única de direito de propriedade como acontece atualmente. E supõe que este experimentalismo econômico prospere num contexto de aprofundamento da democracia, já que as formas existentes de democracia representativa, na ótica de Unger, desaceleram a transformação da sociedade pela política e mantém a sociedade num patamar relativamente baixo de mobilização política. As formas institucionais alternativas defendidas por ele, ao contrário, são desenhadas para acelerar a transformação da sociedade pela política e para aumentar de forma duradoura e institucionalizada a mobilização política da sociedade. (UNGER, 2004) (especialmente o capítulo 5).

16 Para uma análise clássica e detalhada das dificuldades políticas resultantes do desarranjo da estrutura socioeconômica da social democracia em toda a Europa, Anderson e Camiller (1996). Os títulos dos capítulos dedicados ao exame dos três países escandinavos considerados historicamente o baluarte da social democracia europeia são sintomáticos: "Suécia: Depois da idade de ouro", "Noruega: Mudança de modelo" e "Dinamarca: Fim de um idílio?"

${ }^{17}$ Portanto, a ideia democrática defendida por Unger, que é sempre procurar aproveitar a área de intersecção entre o experimentalismo econômico e o experimentalismo político, postula romper esse compromisso social democrata. Isso seria, na sua visão, por assim dizer, uma crítica interna desse mundo das democracias do primeiro mundo. Mas ao mesmo tempo, está implícita nesta proposta, uma "crítica externa" - não do ponto de vista deste mundo, mas de um ponto de vista fora dele - que afirma que este é o mundo em que tudo que é público - o mundo da construção coletiva - foi abandonado, e que o mundo da inovação ocorre no terreno da cultura e da subjetividade. A ideia de que a política se torna pequena para que as pessoas possam se tornar grandes. Para Unger, esta concepção que anima o que se concebe como progressista hoje é inaceitavelmente restritiva tanto das possibilidades práticas como espirituais.
} 
entre concepção e execução, que mistura concorrência e cooperação e que transforma a vida produtiva numa experiência de aprendizagem e inovação permanente. Esse vanguardismo produtivo prospera em setores relativamente isolados das sociedades e com pouca ajuda do Estado. A grande questão, para Unger, é saber se esta mudança no padrão produtivo vai ocorrer só em "ilhas" ou se ela pode ser generalizada para a economia como um todo. E nesse caso, a resposta é herética para os padrões dominantes: para ser generalizada ela precisa de ajuda pública $^{18}$. Mas essa ajuda não pode vir na forma de uma direção centralizada ou de uma distribuição de favores, ou ainda de uma política industrial e comercial no modelo das economias dos tigres asiáticos. E nesse ponto está o problema: como se pode conceber uma forma de associação entre o poder público e a iniciativa privada que ajude a difundir e radicalizar o experimentalismo ao invés de dirigi-lo ou constrangê-lo ${ }^{19}$.

A terceira oportunidade política para o desenvolvimento desse projeto é a ameaça periódica que a instabilidade financeira tem imposto à economia real. A oscilação dos fluxos financeiros se torna mais custosa à medida que eles se internacionalizam. Dessa forma, acabam ressuscitando o debate dos anos 30 e 40 sobre reformas institucionais que mudassem a relação entre a finança e a economia real ${ }^{20}$.

A esse conjunto de oportunidades práticas talvez seja possível acrescentar uma que diz respeito a questão do destino das nações, não só como economias, mas como civilizações, como no caso dos grandes países continentais marginalizados do tipo do Brasil. O que está em jogo em última instância nesse debate sobre a tese da convergência e a da indefinição institucional da economia não é apenas a existência de uma alternativa ao compromisso e discurso social democrata. Mas sim, a possibilidade de criação no mundo de formas alternativas de organização da vida social, sustentadas ou informadas por instituições diferentes a ser desenvolvidas em grandes teatros como o Brasil. Para o aproveitamento de todas essas oportunidades do mundo contemporâneo, intelectuais e políticas, é indispensável atentar para a dialética entre o local e o

\footnotetext{
${ }^{18}$ Uma discussão atualizada a respeito da capacidade de investimento do Estado pode ser encontrada em Mazzucato (2013).

${ }^{19}$ Essa questão envolve três temas relacionados: desenvolvimento, Estado e política industrial. Para Unger uma discussão séria e fecunda deles requer que se compreenda a sua real natureza: não se concebe e materializa um Estado para depois se definir o que fazer com ele. A criação ou transformação de um agente institucional como o estado ocorre no bojo de um processo político que procura reorientar o modelo existente de sociedade e de desenvolvimento - não importa em que direção. Nesse contexto o tema da reforma do estado ganha outra dimensão. A ideia é a de que se reforma o Estado para que ele cumpra alguma tarefa. Assim se se deseja deslanchar um tipo de política industrial voltada para o desenvolvimento tem de se ter um agente institucional capaz de realizar as funções requeridas por tal processo. Ver Unger (1999, p. 46-48; 149-162).

${ }^{20} \mathrm{O}$ que até então era praticamente um debate acadêmico, virou uma necessidade por causa da crise econômica sistêmica que estamos experimentando desde 2008. Para Unger essa crise cria uma oportunidade para se avançar em dois projetos com amplas conseqüências institucionais: a revisão dos acordos do período pós-segunda guerra mundial, objetivando proporcionar arranjos internacionais mais abertos a experimentos e a alternativas e reformar as instituições que definem as economias de mercado, procurando ligar institucionalmente o universo das finanças ao da produção e não apenas criar meios de regular mais o mercado financeiro. Esta crise evidencia de maneira muito particular as justificativas e os objetivos de uma das questões centrais do pensamento de Unger: a inovação institucional (UNGER, 2009). Para a compreensão do desenvolvimento histórico do sistema de regulação do sistema financeiro internacional pós-segunda guerra mundial, ver Belluzzo (1995).
} 
universal, entre uma política interna e uma política externa que se reforcem mutuamente. E que seja capaz de enfrentar analiticamente a relação centro e periferia descartando o fatalismo histórico.

\section{Considerações finais}

Buscamos refletir a respeito das ideias de San Tiago Dantas e Roberto Mangabeira Unger no que diz respeito às propostas dos autores acerca da política exterior do Brasil e nesse sentido, defendemos que a principal aproximação existente entre ambos é a visão dialética dos autores sobre política exterior e a política interna ou doméstica. Na verdade, Dantas e Unger têm como preocupação a inserção do Brasil no plano internacional e para isso é imprescindível que tal inserção tenha a marca emblemática da independência, da autonomia, portanto, que se traduz no diálogo travado com os demais países.

A questão primordial enfrentada por San Tiago Dantas foi avançar a democracia social no Brasil entre o que ele considerava dois ataques: o dos setores conservadores contrários à dinâmica de democratização iniciada pelo trabalhismo brasileiro e o dos setores da esquerda mais radical que ele classificou como "negativa", justamente por insistir em um ritmo de transformação estrutural da sociedade brasileira que em sua avaliação colocava em risco o compromisso com a democracia e todo o processo de auto-afirmação nacional no plano internacional. Daí a sua proposta de constituição de uma esquerda "positiva".

Analisando retrospectivamente, Dantas não deixa de ter alguma razão, tendo em vista que o golpe civil-militar de 64 acabou não só rompendo com a lógica de inclusão material do período trabalhista, como colocou o país em um grande inverno autoritário. De toda sorte, Dantas acabou derrotado pela história. Não apenas porque não conseguiu evitar a derrota do governo João Goulart para os conservadores, mas também porque o que podemos classificar hoje de esquerda "positiva" não conseguiu reconectar o país com a dinâmica de mudanças sociais rompida em 64.

$\mathrm{O}$ contexto de ação intelectual e política de Roberto Mangabeira Unger é o da redemocratização política do país e da sua luta por uma orientação mais radical do que aquela que acabou norteando a "transação conservadora", para usarmos as palavras de Florestan Fernandes, e formando o consenso que domina a política brasileira até hoje: a do lento, gradual e progressivo redistributivismo marginal de recursos, sem ambicionar mexer com o fundo causal de uma das mais injusta e irresponsável sociedade do Ocidente. A formulação de Unger por um novo modelo de organização institucional da economia e da política na sociedade brasileira como prenúncio de um caminho alternativo ao do Atlântico Norte ainda não encontrou ressonância na vida brasileira.

Mas há algo mais profundo que une San Tiago Dantas e Roberto Mangabeira Unger, 
apesar de todas as possíveis dissonâncias entre eles. Os dois compartilham uma inspiração: aquela que enxerga em Quixote, personagem central do livro homônimo de Miguel de Cervantes, o exemplo de "um apólogo da alma Ocidental", para Dantas, na qual "Ideologias e religiões, projetos de renovação política, estética e moral trazem, no mundo moderno, a mensagem dos cavaleiros andantes”, segundo Unger. Talvez, por isso, a premissa central das idéias de ambos os teóricos aqui examinados é a de que a política exterior deve ser, antes de tudo, expressão e instrumento de um projeto de país. Tudo nela deve explicitar, de uma forma ou de outra, uma estratégia nacional de desenvolvimento. 


\section{Referências}

ANDERSON, Perry. Afinidades Seletivas. São Paulo: Boitempo, 2002.

ANDERSON, Perry; Camiller, Patrick. Um Mapa da Esquerda na Europa Ocidental. Rio de Janeiro: Contraponto, 1996.

BELUZZO, Luis Gonzaga. O Declínio de Bretton Woods e a Emergência dos Mercados "Globalizados". Economia e Sociedade, Campinas, (4), 1995.

CUI, Zhiyuan, Prefácio, In: UNGER, R. M. Política: Os Textos Centrais. São Paulo: Boitempo, 2001.

DANTAS, San Tiago. A Política Externa Independente. Rio de Janeiro: Civilização Brasileira, 1962.

. Homem de visão. Rio de Janeiro: Visão, 1963.

. Perfis Parlamentares. Brasília: Câmara dos Deputados, 1983.

FUKUYAMA, Francis. O Fim da História e o Último Homem. Rio de Janeiro: Rocco, 1992.

LOVIN, Robin; PERRY, Michael (Orgs.), Critique and Constrution: A Simposium on Roberto Unger's Politics. New York: Cambrigde University Press, 1987.

MAZZUCATO, Mariana. The Entrepreneurial State: Debuking public vs private sector miths. New York: Anthem Press, 2013.

SERRA, Carlos Henrique Aguiar. O pensamento politico de San Tiago Dantas; uma análise crítica da conjuntura politico-ideológica de 1958-1964. Dissertação de Mestrado. PUC (Rio de Janeiro), 1991.

TEIXEIRA, Carlos Sávio. Da cópia institucional à vitalidade organizada: O Brasil de Unger. Revista USP, n. 99, 2013.

UNGER, R. Mangabeira. A Reinvenção do Livre Comércio. Rio de Janeiro: Ed. da FGV, 2010.

Aproveitando a crise para refazer o mercado. Jornal do Brasil, 08/02/2009.

False necessity: Anti-necessitarian social theory in the service of radical democracy. Londres: Verso, 2004.

. Por que o Brasil não tem política exterior? Folha de São Paulo, 12/03/2002.

A segunda via: Presente e futuro do Brasil. São Paulo: Boitempo, 2001.

Democracia realizada: A alternativa progressista. São Paulo: Boitempo, 1999.

A alternativa transformadora: como democratizar o Brasil. Rio de Janeiro: 
Guanabara, 1990.

Social Theory: Its Task and its Situation. Cambridge: Cambridge University Press, 1987.

Plasticity into Power: Comparative-historical studies on the institucional conditions of economic and military success. Cambridge: Cambridge University Press, 1987. 